\title{
STUDI ANALISIS SISTEM PENTANAHAN EKSTERNAL PADA GEDUNG UNIT PELAKSANA TEKNIS TEKNOLOGI INFORMASI DAN KOMUNIKASI UNIVERSITAS LAMPUNG
}

\author{
Riza Ariesta, Dikpride Despa, Herri Gusmedi, Lukmanul Hakim \\ Jurusan Teknik Elektro Fakultas Teknik Universitas Lampung \\ rizaariesta18@gmail.com,despa@eng.unila.ac.id,herri.gusmedi@eng.unila.ac.id., \\ lukmanul.hakim@eng.unila.ac.id
}

\begin{abstract}
Abstrak
Analisis sistem pentanahan gedung Unit Pelaksana Teknis Teknologi Informasi dan Komunikasi Universitas Lampung (UPT TIK UNILA) menyesuaikan dengan kondisi gedung, penggunaan gedung, dan sistem pentanahan yang ada saat ini. Analisis dilakukan dengan cara melakukan pengumpulan data curah hujan, data gedung dan data pentanahan. Luas daerah yang menarik sambaran petir $9.742,21 \mathrm{~m}^{2}$, jumlah sambaran petir 0,079 per hari per $\mathrm{km}^{2}$ dan kemungkinan gedung tersambar petir 0,4 sambaran petir per tahun. Hasil analisis penelitian pada gedung UPT TIK UNILA membutuhkan sistem pentanahan eksternal menggunakan sistem franklin dengan batang pentanahan parallel dengan perkiraan biaya Rp.3.429.435,-
\end{abstract}

Kata kunci : Sistem Pentanahan, Kmponen Sistem Pentanahan, UPT TIK.

Abstract

Analysis of the building grounding system Unit Service Technic Technology Information and Communication, University of Lampung (UPT TIK UNILA) adapted with the application building space, grounding system and grounding systems technology at now. Attractive area $9.742,21 \mathbf{m}^{2}$, amount of lightning strikes 0.079 day $/ \mathrm{km}^{2}$ and possibility lightning strike to building 0.4 lightning strikes / year Procedure performed by collecting rainfall data, building data and grounding data. Results of research UPT TIK UNILA require external grounding system franklin with parallel earthing rod with estimated cost Rp.3.429.435,-

Keywords: grounding system, grounding system components, UPT TIK UNILA

\section{Pendahuluan}

Dalam sebuah gedung terdapat penggunaan barang elektronik yang menggunakan energi listrik agar dapat bekerja. Penggunaan energi listrik disesuaikan dengan spesifikasi, kapasitas, dan kebutuhan peralatan elektronik. Ketika terjadi aliran energi listrik yang tidak sesuai maka peralatan tidak dapat bekerja secara normal.

Salah satu penyebab ketidaksesuain energi listrik yang mengalir adalah terjadinya sambaran petir disekitar gedung. Untuk menghindari bahaya sambaran petir yang dapat merusak peralatan elektronik digunakan sistem pentanahan eksternal.

Gedung UPT TIK UNILA didalamnya terdapat banyak perangkat elektronik, sehingga diperlukan sistem pentanahan eksternal untuk mengalirkan kelebihan muatan akibat sambaran petir yang terjadi disekitar gedung. Dalam penelitian ini dibahas tentang analisis sistem pentanahan yang sesuai pada gedung UPT TIK UNILA berikut biaya bahan dari pemasangan sistem pentanahan eksternal.

\section{TINJAUAN PUSTAKA}

\subsection{Petir}

Petir adalah suatu fenomena alam, yang pembentukannya berasal dari terpisahnya muatan di dalam awan kumolonimbus. Awan kumolonimbus adalah sebuah awan vertikal menjulang yang sangat tinggi, padat, dan terlibat dalam badai petir dan cuaca dingin lainnya[11]. Umumnya muatan negatif terkumpul dibagian bawah dan ini menyebabkan terinduksinya muatan positif di atas permukaan tanah, sehingga membentuk 
medan listrik antara awan dan tanah. Terdapat 2 teori yang mendasari proses terjadinya petir :

1. Proses Ionisasi

Sambaran Petir merupakan peristiwa alam yaitu proses pelepasan muatan listrik (Electrical Discharge) yang terjadi di atmosfer, hal ini disebabkan berkumpulnya ion bebas bermuatan negatif dan positif di awan, ion listrik dihasilkan oleh gesekan antar awan dan juga kejadian ionisasi ini disebabkan oleh perubahan bentuk air mulai dari cair menjadi gas atau sebaliknya, bahkan padat (es) menjadi cair. Ion bebas menempati permukaan awan dan bergerak mengikuti angin yang berhembus, bila awan-awan terkumpul di suatu tempat maka awan bermuatan ion tersebut akan memiliki beda potensial yang cukup untuk menyambar permukaan bumi maka inilah yang disebut petir.

\section{Gesekan Antar Awan}

Pada awalnya awan bergerak mengikuti arah angin, selama proses bergeraknya awan ini maka saling bergesekan satu dengan yang lainya, dari proses ini terlahir elektron-elektron bebas yang memenuhi permukaan awan. Proses ini bisa di simulasikan secara sederhana pada sebuah penggaris plastik yang digosokkan pada rambut maka penggaris ini akan mampu menarik potongan kertas. Pada suatu saat awan ini akan terkumpul di sebuah kawasan, saat inilah petir dimungkinkan terjadi karena elektron-elektron bebas ini saling menguatkan satu dengan lainnya. Sehingga memiliki cukup beda potensial untuk menyambar permukaan bumi.

Ancaman sambaran petir pada peralatan perlu diwaspadai dan upaya perlindungan terhadap instalasi, bangunan yang berisikan peralatan elektronik seperti pada industri, bank, instalasi penting, militer, bahkan perorangan perlu ditingkatkan. Sambaran petir pada tempat yang jauh $+1,5 \mathrm{~km}$ sudah dapat merusak sistem elektronika dan peralatan, seperti instalasi komputer, telekomunikasi kantor dan instrumentasi serta peralatan elektornik lainnya.

\subsection{Sistem Pentanahan Franklin}

Sistem pentanahan sistem franklin menempatkan sebuah batang penangkal petir dengan ujungnya dibuat runcing di bagian teratas dari bagian yang akan dilindungi. Ujung batang penangkal petir ini dibuat runcing dengan tujuan agar pada keadaan dimana terjadi aktivitas penumpukan muatan di awan, maka diujung itulah akan terinduksi muatan dengan rapat muatan yang relatif lebih besar bila dibandingkan dengan rapat muatan dari muatan-muatan yang terdapat pada bagianbagian lain dari bangunan, dengan demikian dapat diharapkan bahwa kilat akan menyambar ujung dari batang penangkal petir itu terlebih dahulu. Batang penangkal petir ini kemudian di ketanahkan melalui penghantar turun ke elektroda pengetanahan. Tujuan dari penghantar turun dan elektroda pengetanahan adalah sebagai jalan "by pass" bagi muatan bumi dan juga arus kilat untuk keluar atau memasuki bumi sehingga muatan bumi atau arus kilat tidak mengambil jalan melalui bagian-bagian lain dari bangunan yang bersangkutan.

Penangkal Petir Franklin merupakan rangkaian jalur konduktor dari atas bangunan ke sisi bawah / grounding dengan jalur kabel tunggal (satu buah kabel BC penurunan) terlihat pada gambar 1. dengan dasar pemikiran bahwa petir akan condong menyambar dari sisi atas, sehingga efisiensi dan penghematan material bahan bisa dilakukan. Sistem Franklin Rod berupa kerucut tembaga dengan daerah perlindungan berupa kerucut imajiner agar daerah perlindungan besar. Franklin Rod dapat dilihat berupa tiang-tiang di bubungan atap bangunan. Pengamanan bangunan terhadap sambaran kilat dengan menggunakan sistem penangkal petir Franklin merupakan cara yang tertua namun masih sering digunakan karena hasilnya dianggap cukup memuaskan, terutama untuk bangunan-bangunan dengan bentuk tertentu, seperti misalnya : menara, gereja dan bangunan-bangunan lain yang beratap runcing.

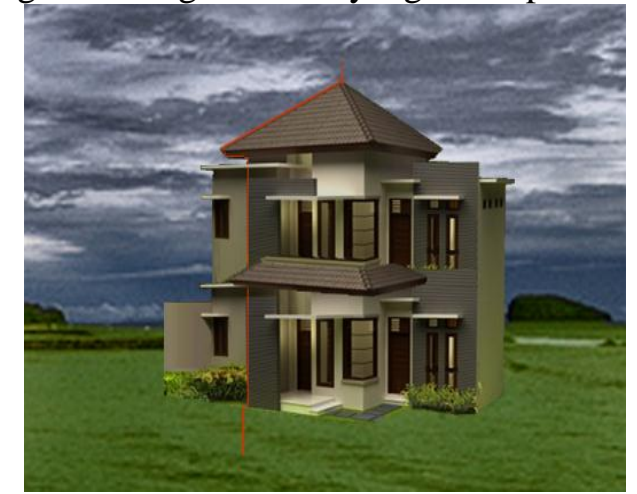

Gambar 1. Sistem Pentanahan Sistem Franklin. [5]

\section{PERHITUNGAN DAN PEMBAHASAN}

Dalam penelitian dilakukan perhitungan dan analisa mengenai perencanaan instalasi penangkal petir sistem franklin pada Gedung UPT TIK UNILA. Adapun kondisi, situasi dan lokasi dari gedung tersebut adalah sebagai berikut: 
1.Gedung UPT TIK UNILA terletak di Kota Bandar Lampung dimana secara geografis Kota Bandar Lampung terletak pada $5^{0} 20^{\prime}$ sampai dengan $5^{0} 30^{\prime}$ ' lintang selatan dan $105^{\circ} 28^{\prime}$ sampai dengan $105^{\circ}$ 37' bujur timur.[9]

2.Konstruksi gedung terdiri dari beton bertulang dengan ukuran :

Tinggi gedung $=19$ meter

Panjang gedung $=39,50$ meter

Lebar gedung $=19,1$ meter

3. Gedung berdiri di daerah dataran rendah dengan ketinggian 700 meter dari permukaan laut. [10]

4.Curah hujan per tahun di daerah gedung memiliki rata-rata 133 hari pertahun. [8]

5.Hari guruh per tahun (IKL) untuk daerah Bandar Lampung : 260 hari pertahun. [7]

Untuk merencanakan instalasi penangkal petir, sebelumnya ditentukan tingkat kebutuhan pada bangunan tersebut dengan cara :

1.Menentukan kepadatan sambaran petir $(\mathrm{Ft}) .[12]$

$\mathrm{Ft}=0,25 . \mathrm{T}$ sambaran $/ \mathrm{km} 2 / \mathrm{tahun}$

$\mathrm{Ft}=0,25 \times 260$

$=65 \mathrm{sambaran} / \mathrm{km}^{2} / \mathrm{tahun}$

2. Menentukan tingkat perkiraan bahaya Gedung UPT TIK UNILA

Untuk mengetahui diperlukan atau tidaknya Gedung UPT TIK UNILA menggunakan instalasi penangkal petir dapat ditentukan berdasarkan nilai perkiraan bahaya

$(\mathrm{R})=\mathrm{A}+\mathrm{B}+\mathrm{C}+\mathrm{D}+\mathrm{E}$

dengan indek-indek sebagai berikut : [9]

1) Indek $A$, penggunaan dan isi

Gedung UPT TIK UNILA merupakan salah satu gedung perkantoran tempat pusat komputer yang digunakan untuk menyimpan arsip dan dokumen penting lainya, nilai $=2$.

2) Indek $B$, konstruksi bangunan

Gedung UPT TIK UNILA termasuk bangunan dengan menggunakan konstruksi beton bertulang dan atap bukan logam, nilai $=2$.

3) Indek $C$, tinggi bangunan

Gedung UPT TIK UNILA mempunyai ketinggian 19 meter, nilai $=4$.

4) Indek $D$, situasi bangunan

Gedung UPT TIK UNILA berdiri di daerah dataran tinggi dengan ketinggian 700 meter dari permukaan laut, nilai $=0$
5) Indek E, pengaruh kilatHari guruh per tahun di daerah Kota Bandar Lampung adalah 260, nilai $=8$

Jadi jumlah $\mathrm{R}=\mathrm{A}+\mathrm{B}+\mathrm{C}+\mathrm{D}+\mathrm{E}=2+$ $2+4+0+8=16$.

Karena nilai $\mathrm{R}=16$ maka indeks perkiraan bahaya pada Gedung UPT TIK UNILA terhadap sambaran petir adalah sangat besar. Dengan sendirinya pengamanan gedung terhadap sambaran petir sangat perlu.

3.Menentukan luas daerah bangunan yang menarik sambaran petir $(\mathrm{Ca})$.

Perhitungan luas daerah bangunan yang menarik sambaran petir dilakukan dengan menggunakan persamaan berikut: [9] $\mathrm{Ca}=(\mathrm{L} \times \mathrm{W})+(4 \mathrm{~L} \times \mathrm{H})+(4 \mathrm{~W} \times \mathrm{H})+$ $4\left(\pi \mathrm{H}^{2}\right)$

Berdasarkan rumus tersebut dan data yang diperoleh mengenai Gedung UPT TIK UNILA dengan tinggi gedung $(\mathrm{H}) 19$ meter, panjang gedung (L) 39,5 meter, dan lebar gedung (W) 19,1 meter maka luas daerah yang menarik sambaran petir adalah:

$\mathrm{Ca}=(39,5 \mathrm{~m} \times 19,1 \mathrm{~m})+((4 \times 39,5 \mathrm{~m}) \mathrm{x}$ $19 \mathrm{~m})+((4 \times 19,1 \mathrm{~m}) \times 19 \mathrm{~m})+4(3,14 \mathrm{x}$ $\left.19^{2}\right) \mathrm{m}^{2}$

$\mathrm{Ca}=(754,45+3002+1451,6+4534,16)$

$\mathrm{m}^{2}$

$\mathrm{Ca}=9.742,21 \mathrm{~m}^{2}$

4.Menentukan perkiraan kemungkinan Gedung UPT TIK UNILA tersambar petir.

Dari luas daerah yang menarik sambaran petir tersebut $(\mathrm{Ca})$, maka kemungkinan daerah Gedung UPT TIK UNILA tersambar petir dapat diketahui dengan menggunakan rumus berikut: [9]

Ps $=\mathrm{Ca} \times \mathrm{NE} \times \mathrm{IKL} \times \mathrm{C} 1$

Karena terkait dengan jumlah sambaran petir per hari per $\mathrm{km}^{2}(\mathrm{NE})$ dengan I untuk Kota Bandar Lampung adalah $0,005^{\circ} 20^{\prime}$ maka dari persamaan : [4]

$$
\begin{aligned}
& \mathrm{NE}=(0,1+0,35 \sin \mathrm{I})(0,4 \pm 0,2) \ldots . .(3.5) \\
& =\left(0,1+0,35 \sin 5,2^{0}\right)(0,4 \pm 0,2) \\
& =(0,1317)(0,4 \pm 0,2) \text { sambaran } \\
& \text { petir/hari/ } \mathrm{km}^{2} \\
& \text { untuk ini diambil nilai maksimum yaitu } \\
& =(0,1317)(0,6) \text { sambaran petir/hari/ } \mathrm{km}^{2} . \\
& =0,079 \text { sambaran petir/hari/ } \mathrm{km}{ }^{2} . \\
& \text { Sehingga: } \\
& \text { Ps = 9.742,21. } 10^{-6} \mathrm{~km} 2 \times 0,079 \times 260 \mathrm{x} \\
& 2,0 \\
& =0,4 \text { sambaran petir/tahun } \\
& \text { Perhitungan Tahun Tersambar Petir : } \\
& \text { 1/0,4 = 2,5 Tahun / Sambaran Petir }
\end{aligned}
$$


5.Menentukan tingkat kebutuhan pengamanan Gedung UPT TIK UNILA terhadap sambaran petir.

Berdasarkan perhitungan di atas maka tingkat kebutuhan pengamanan dari daerah Gedung UPT TIK UNILA adalah berdasarkan persamaan : [9]

$$
\begin{aligned}
& \mathrm{Pr}=\mathrm{Ps} \times \mathrm{C} 2 \times \mathrm{C} 3 \times \mathrm{C} 4 \times \mathrm{C} 5 . \\
& \mathrm{Pr}=0,4 \times 1,4 \times 2 \times 1,5 \times 1,5 \\
& =2,52
\end{aligned}
$$

sehingga tingkat proteksi dari daerah Gedung UPT TIK UNILA termasuk proteksi tingkat III dengan nilai jarak inisiasinya $(\mathrm{D})=$ $20 \mathrm{~m}$.

Dalam perencanaan instalasi penangkal petir pada Gedung UPT TIK UNILA adalah penangkal petir sistem franklin. Proses pemilihan penangkal petir sistem franklin adalah :

Bangunan Gedung UPT TIK UNILA memiliki atap jurai. Dapat digunakan penangkal petir sistem franklin. Tiap-tiap Finial penangkal petir Franklin dihubungkan dengan menggunakan kawat $\mathrm{BC} \pm 10 \mathrm{~mm}^{2}$, dimulai dari ujung atap bangunan sampai dengan tengah atap bangunan. Radius perlindungan ( $\mathrm{Rp}$ ) pada sistem franklin dapat dihitung dengan menggunakan persamaan : [4]

$$
\begin{aligned}
& \mathrm{Rp}=\mathrm{h} \sqrt{ } \pm(\mathrm{D} / \mathrm{h})-1 \ldots \ldots . \\
& \mathrm{Rp}=0,3 \sqrt{ } \pm(20 / 0,3)-1 \\
& \mathrm{Rp}=1,7 \text { meter }
\end{aligned}
$$

Sehingga dapat dihitung luas area perlindungan : [4]

$$
\begin{aligned}
& \mathrm{Ap}=\pi . \mathrm{Rp}^{2} \ldots \ldots \\
& \mathrm{Ap}=3,14.1,7^{2} \\
& \mathrm{Ap}=9,0746 \mathrm{~m}^{2}
\end{aligned}
$$

Luas penghantar turun dari suatu instalasi penangkal petir dengan arus gangguan berlangsung selama 0,001 detik, arus petir maksimum $220 \mathrm{kA}$ dan temperatur konduktor yang diizinkan $1000^{\circ} \mathrm{C}$ adalah dari persamaan : [3]

$\mathrm{A}=\operatorname{Io} \sqrt{ }\left(8,5 \cdot 10^{-6} \mathrm{~S} / \log 10^{(\mathrm{T} / 274)+1)}\right.$

$\mathrm{A}=220.10^{3} \sqrt{\left(8,5.10^{-6} 0,001 / \log 10^{(1000 / 274)+1)}\right.}$

$\mathrm{A}=9,406 \mathrm{~mm}^{2}$

Karena hasil perhitungan didapatkan lebih kecil, maka dapat digunakan kawat atau kabel dengan luas penampang yang mendekati hasil perhitungan dan tidak diizinkan lebih kecil dari hasil perhitungan [2]. Menurut diameter dari penangkal petir yang digunakan maka luas penampang penghantar turun yang cocok untuk penangkal petir ini adalah $10 \mathrm{~mm}^{2}$.

Untuk sistem pentanahan dilakukan beberapa pengukuran tahanan tanah di daerah sekitar Gedung UPT TIK UNILA yang menggunakan Earth Tester Type 3235. Dari hasil pengukuran resistansi pentanahan dapat dicari nilai besarnya tahanan pentanahan dari batang elektroda dengan persamaan : [1]

\begin{tabular}{|c|c|c|c|c|}
\hline No. & $\begin{array}{l}\text { Nama } \\
\text { Barang }\end{array}$ & Volume & $\begin{array}{c}\text { Harga } \\
\text { Satuan } \\
\text { (Rp.) }\end{array}$ & $\begin{array}{c}\text { Jumlah } \\
\text { Biaya } \\
\text { (Rp.) }\end{array}$ \\
\hline 1 & $\begin{array}{c}\text { Kabel } \\
\text { Tembaga } \\
\text { BC 10mm }\end{array}$ & $\begin{array}{c}78,776 \\
\mathrm{~m}\end{array}$ & 13.125 & 1.033 .935 \\
\hline 2 & Klem BC & $\begin{array}{c}147 \\
\text { Buah }\end{array}$ & 1.500 & 220.500 \\
\hline 3 & $\begin{array}{l}\text { Splitzer / } \\
\text { Finial } \\
\text { Franklin } \\
\text { 3/4 Inchi }\end{array}$ & $\begin{array}{c}37 \\
\text { Buah }\end{array}$ & 50.000 & 1.850 .000 \\
\hline 4 & $\begin{array}{c}\text { Elektroda } \\
\text { Pentanahan } \\
\text { Tembaga }\end{array}$ & 2 Buah & 150.000 & 300.000 \\
\hline 5 & $\begin{array}{c}\text { Pipa PVC } \\
0,5 \text { Inchi }\end{array}$ & $1 \mathrm{Buah}$ & 20.000 & 20.000 \\
\hline 6 & $\begin{array}{c}\text { Klem pipa } \\
\text { PVC } 0,5 \\
\text { Inchi }\end{array}$ & 5 Buah & 5.000 & 5.000 \\
\hline \multicolumn{4}{|c|}{ Total Biaya } & 3.429 .435 \\
\hline
\end{tabular}

$$
\begin{aligned}
& \mathrm{X}=(\mathrm{L} /(\mathrm{Ln} 48 \mathrm{~L} / \mathrm{a}-1)) / \mathrm{d} \\
& \mathrm{X}=(\mathrm{L} /(\mathrm{Ln} 48 \mathrm{~L} / \mathrm{a}-1)) / \mathrm{d} \\
& \mathrm{X}=(0,5 /(\operatorname{Ln} 48.0,5 / 0,012-1)) / 7,81 \\
& X=(0,5 /(-1,959)) / 7,81 \\
& X=-0,255 / 7,81 \\
& X=-0,0326 \\
& \text { Dan ; } \\
& \mathrm{R}=(1+\mathrm{x}) / 2 \mathrm{ohm} \\
& \mathrm{R}=(1+(-0,0326)) / 2 \\
& \mathrm{R}=0,9674 / 2 \\
& \mathrm{R}=0,4837 \mathrm{ohm}
\end{aligned}
$$

Bahan-bahan dan material yang dibutuhkan dalam perencanaan instalasi penangkal petir ini adalah :

Tabel 1. Bahan Sistem Pentanahan dan Perkiraan Biaya

\section{PENUTUP}

\subsection{Kesimpulan}

Hasil analisis dan pembahasan perencanaan instalasi penangkal petir Gedung UPT TIK UNILA dapat disimpulkan sebagai berikut:

1.Berdasarkan hasil perhitungan diperoleh besarnya indeks perkiraan bahaya 16 sehingga mempunyai tingkat bahaya yang tergolong besar dan membutuhkan suatu instalasi penangkal petir yang baik dan andal. 
2.Dalam satu tahun kepadatan sambaran petir di Kota Bandar Lampung sebesar 65 sambaran $/ \mathrm{km}^{2} /$ tahun.

3.Luas daerah yang menarik sambaran petir pada daerah sekitar gedung UPT TIK UNILA sebesar 9.742,21 $\mathrm{m}^{2}$ dengan jumlah sambaran petir 0,079 per hari per $\mathrm{km}^{2}$ dan kemungkinan gedung tersambar petir 0,4 sambaran petir per tahun.

4.Jenis penangkal petir yang diusulkan digunakan Franklin, karena gedung tersebut mempunyai atap yang luas berbentuk jurai.

5. Total perkiraan biaya untuk pemasangan sistem pentanahan pada Gedung UPT TIK UNILA adalah Rp. 3.429.435,- (Tiga Juta Empat Ratus Dua Puluh Sembilan Ribu Empat Ratus Tiga Puluh Lima Rupiah)

\subsection{Saran}

Berdasarkan hasil perencanaan dan kesimpulan, maka penulis mengemukakan beberapa saran yaitu:

1.Sehubungan penggunaan alat elektronik di UPT TIK UNILA terbilang banyak, untuk itu diperlukan keselamatan gedung dari bahaya sambaran petir, dengan memasang penangkal petir.

2.Karena Gedung UPT TIK UNILA berada didaerah yang mempunyai hari guruh dan curah hujan yang cukup tinggi, sebaiknya dilakukan pemeliharaan dan pemeriksaan secara berkala untuk menjaga atau dalam mengamankan gedung dari bahaya sambaran petir yang sewaktu-waktu dapat terjadi.
Daftar Pustaka:

[1] A.S. Pabla, Sistem Distribusi Daya Listrik, Erlangga Jakarta, 1994.

[2] Andrias, Theoretisches Kodieren. Textanalyse in der Grounded Theory, 2000

[3] Departemen Pekerjaan Umum, Pedoman Perencanaan Instalasi Penangkal Petir, Jakarta : Yayasan Bandung, Penerbit PU, 1987.

[4] Golde, R.H Lightning. Volume 2. London : Academic Press Inc. 1981

[5] Http://antipetir.com/penangkal-petir-rumahkonvensional, diunduh tanggal 27 Juli 2013

[6] Https://id.wikipedia.org/wiki/Kota_ Bandar_Lampung diunduh tanggal 17 Oktober 2013

[7] Https://ml.scribd.com/doc/229820415/ ANALISA-PEMETAAN-KONTUR-DANKERAPATAN-PETIRDENGANLIGHTNING-2000-DAN-METODEKRIGINGDI-SURABAYA-TAHUN-2000. Diunduh tanggal 17 Maret 2014

[8] Observatorium BMKG dan Observatorium Polinela

[9] Standar National Fire Protection Association, 1994, -781.

[10]Wikimapia.org/\#lang=en\&lat=-5.362719\& lon $=105.241433 \& \mathrm{z}=18 \& \mathrm{~m}=\mathrm{b}]$

[11]Wikipedia, Awan Kumolonimbus diunduh tanggal 9 September 2015

[12] Zoro Reynaldo.co. Computation of Lightning Protection, Bandung.pdf. 1999. 2000. 